\title{
Considerações acerca da tecnologia assistiva no cenário educacional brasileiro
}

\author{
David dos Santos Calheiros* \\ Enicéia Gonçalves Mendes** \\ Gerusa Ferreira Lourenço***
}

\section{Resumo}

A partir da demanda crescente de produção de conhecimento teórico e prático sobre tecnologia assistiva (TA) nos seus múltiplos contextos no Brasil, o presente texto tem por objetivo apresentar considerações a respeito dessa temática no campo da educação. Por meio de uma revisão de estudos sobre conceitos e práticas, são relatadas consideraçôes quanto as definiçôes utilizadas, políticas que legitimam essa interface de uso na educação e investigações sobre práticas já realizadas, destacando três grandes obstáculos identificados: a imprecisão do atual conceito de TA, as dificuldades no acesso aos recursos e a falta de formação dos profissionais envolvidos. A direção tomada indica que há cada vez mais demandas pela manutenção dos investimentos realizados no país, como capacitação de recursos humanos e desenvolvimento de açôes mais assertivas quanto ao uso mais eficiente desses recursos no contexto educacional brasileiro, no sentido de que ele realmente atinja seus objetivos na garantia de autonomia e participação nas atividades cotidianas.

Palavras-chave: Educação Especial; Tecnologia assistiva; Formação.

* Professor mestre na Universidade Estadual de Ciências da Saúde de Alagoas, Maceió, Alagoas, Brasil.

** Professora doutora na Universidade Federal de São Carlos, São Carlos, São Paulo, Brasil.

*** Professora doutora na Universidade Federal de São Carlos, São Carlos, São Paulo, Brasil. 


\section{Considerations about the assistive technology in the brazilian educational scenario}

\section{Abstract}

The growing demand for production of theoretical and practical knowledge about assistive technology (AT) throughout the multiple contexts in Brazil calls, in the education field, for researches on this subject. Based on a review of studies that presents concepts and practices, we bring considerations about definitions and policies, which legitimize this interface in education and practical investigations already carried out, highlighting three major obstacles identified: the vagueness of the current AT concept; difficulties in to access the resources; and the lack of professionals involved trained to use these devices. This study indicates the increase of demands for the maintenance of the investment throughout the country, such as the training of the human resources and the development of more assertive actions concerning the effectiveness use of these resources in the Brazilian educational context, in order to ensure the autonomy and participation of students with disabilities in their daily activities.

Keywords: Special Education; Assistive technology; Professionals preparation.

\section{Introdução}

Com vistas a ampliar o debate acerca do desenvolvimento da área de Tecnologia Assistiva (TA) no contexto educacional brasileiro, o objetivo deste estudo consistiu em traçar consideraçóes quanto à sua especificidade conceitual no país, além de abordar aspectos inerentes ao processo de uso desse tipo de equipamento nas atividades desenvolvidas no âmbito escolar. A literatura tem indicado que ainda não há um uso efetivo de forma generalizada dos recursos de TA no contexto educacional no país devido a diversos fatores, como características próprias do equipamento educacional, do nível de ensino, das demandas e características dos alunos alvo e do próprio domínio no uso pelos professores. Enveredando por essas referências e subsidiados pelas investigaçóes do grupo de pesquisa no qual os autores são vinculados, três aspectos podem ser descritos como obstáculos centrais a essa questão:

- As dificuldades quanto à compreensão do que vem a ser TA;

- Barreiras quanto ao acesso/provisão dos recursos de TA às escolas;

- A formação dos professores e profissionais envolvidos com o atendimento aos alunos com deficiência no contexto escolar.

\section{As dificuldades quanto à compreensão do que vem a ser tecnologia assistiva}

No atual contexto brasileiro, a TA tem sido considerada como uma área promissora e de grande relevância social, inclusive pelos órgãos governamentais que têm investido muito no fomento ao seu desenvolvimento. Essa informação transmite ex- 
pectativas positivas aos profissionais e pesquisadores da área, que veem sua área de estudo crescer e tomar visibilidade nacional, mas, sobretudo, para as pessoas que possuem comprometimentos funcionais (como pessoas com deficiências ou que apresentam mobilidade reduzida), que, em muitos casos, podem ter a sua plena participação social potencializada, por meio de produtos, recursos, metodologias, estratégias, práticas e serviços de TA.

$O$ interesse pela TA em território nacional iniciou-se em meados da década de 70 do século XX (LAUAND, 2005; TOYODA; LOURENÇO, 2008), principalmente com o viés da reabilitação, concebida no sentido de capacitar o sujeito para a realização de atividades cotidianas. Assim, a preocupação era resolver os problemas de ordem funcional de pessoas idosas e com deficiência, por meio da criação e implementaçáo de instrumentos e recursos tecnológicos acessíveis às suas necessidades, com a finalidade de lhes permitir a superaçáo das barreiras que prejudicavam a participação nos diferentes ambientes e contextos sociais.

No espaço educacional, com destaque para as práticas realizadas diretamente com a população-alvo da Educação Especial fortemente ainda nos contextos institucionais, a prática de diferenciação de materiais e uso de adaptaçôes para a realização de atividades também era presente, por exemplo, na educação de pessoas com deficiência visual.

Assim, apesar dessas intervenções na prática, a área foi ganhando interesse e nota-se o crescimento de investimentos científicos a partir da década de 1990, embora ainda houvesse grande imprecisão terminológica e o termo TA ainda não fosse usado, pelo menos não oficialmente no Brasil (CASTRO; SOUZA; SANTOS, 2011).

Essa constituiçấo ainda desorganizada do campo levou muitos pesquisadores brasileiros a desenvolver estudos com essa perspectiva, mas utilizando diferentes termos e conceitos tais como recursos de comunicação alternativa, recursos pedagógicos adaptados, mobiliário adaptado, acessibilidade e informática acessível, como mencionou Manzini (2011), mas não sob o rótulo de TA. Porém, todos esses recursos buscavam soluçóes e alternativas mais eficazes no ganho de funcionalidade de seus usuários.

Essa multiplicidade terminológica, embora tenha contribuído para o avanço e discussão do campo no país, favoreceu o seu desconhecimento pela falta de integração entre os diferentes atores das várias áreas do conhecimento científico envolvidas nesse assunto. Soma-se a isso o fato de que, por muitos anos, essa discussão ficou restrita aos profissionais da saúde (RODRIGUES; ALVES, 2013), em especial aqueles relacionados à reabilitação (terapeutas ocupacionais, fisioterapeutas, fonoaudiólogos) considerados os únicos especialistas nessa área de estudo na época.

Outro detalhe importante é a influência da importação de termos e conceitos norte-americanos e europeus para o Brasil, já que esses países eram as grandes referências na área da TA, como ainda são nos dias atuais. Para exemplificar alguns usavam os termos "tecnologia de apoio" e "ajudas técnicas", originários da literatura europeia (EASTIN, 2005; EUSTAT, 1999; BRASIL, 2009a), enquanto outros utilizavam o termo "tecnologia assistiva", proveniente do contexto norte-americano (PUBLIC 
LAW 108-364, 2004). Em linhas gerais, não há diferenças cruciais entre esses termos, pois todos eles percebem a área a partir de uma compreensão que vai além da dimensão exclusiva do recurso, englobando também uma preocupação com os serviços, estratégias e metodologias. Entretanto, a falta de padronização nos termos e conceitos dificultava o avanço na constituição do campo no país.

No Brasil, embora tenha ocorrido a importação de termos de outros países e estes, de uma forma ou de outra, influenciaram a legislação brasileira, a dimensão conceitual adotada diferia tanto da concepçáo norte-americana quanto europeia, evidenciado nas primeiras publicaçôes oficiais brasileiras (BRASIL, 1999, 2004), e não incluíam as práticas envolvidas no processo como inerentes a sua conceituação. Desse modo, fazia-se necessário uma ressignificação dos termos e conceitos utilizados pela política brasileira. Ademais, havia necessidade de uma organização de diretrizes para essa área de conhecimento da TA.

Frente a essa necessidade, o Comitê de Ajudas Técnicas (CAT), instituído em 2006, sob exigência do Decreto 5.296 (BRASIL, 2004), constituiu-se como o órgão responsável por mobilizar esse processo de mudanças e pelo desenvolvimento da área da TA no Brasil. Entre as ações executadas, pode-se mencionar a adoção oficial da expressão "Tecnologia Assistiva" no cenário brasileiro, em detrimento ao termo "Ajudas Técnicas".

Além disso, o CAT foi responsável por elaborar o atual conceito de TA no Brasil:

Tecnologia Assistiva é uma área do conhecimento, de característica interdisciplinar, que engloba produtos, recursos, metodologias, estratégias, práticas e serviços que objetivam promover a funcionalidade, relacionada à atividade e participação, de pessoas com deficiência, incapacidades ou mobilidade reduzida, visando sua autonomia, independência, qualidade de vida e inclusão social. (BRASIL, 2007, ata da III reunião, linhas 225-230).

Esse conceito é mais lato do que aqueles anteriormente publicados no Decreto 3.298 (BRASIL, 1999) e no Decreto 5.296 (BRASIL, 2004), pois ressalta a característica interdisciplinar da área da TA, permitindo o envolvimento com profissionais de vários campos do conhecimento científico. Nesse sentido, pelo menos em nível conceitual, tentava-se anular o caráter dominante que os profissionais da saúde possuíam até então em relaçáo a esse contexto de atuação.

Ademais, o atual conceito brasileiro de TA náo se resume essencialmente ao produto ou recurso, e inclui em uma perspectiva horizontal, também as metodologias, as estratégias e as práticas e serviços. Nesse aspecto, a definição brasileira passou a ser mais ampla, o que pode causar confusáo, porque essa concepção invade outros campos de conhecimento já consolidados, que também lidam com estratégias, práticas e serviços direcionados a pessoas com deficiência, tais como os campos da Educação e Reabilitação. Assim, embora se reconheça a evolução conceitual que perpassa a TA no Brasil, concordamos com Galvão Filho (2013, p. 28) que é necessário ainda buscar "uma maior precisão conceitual que, ao mesmo tempo em que se apoie 
numa concepção e conceituação ampla e interdisciplinar de TA, igualmente distinga as fronteiras, percebendo e buscando identificar com crescente clareza também o que não é TA". Essa preocupação do autor, em nossa perspectiva, deve ganhar força, pois a TA passou de um período revelado por um forte desconhecimento social para outro em que os setores governamentais mostram-se interessados em financiar propostas e soluções que contribuam para o bem social, assim como para o crescimento e desenvolvimento dessa área do conhecimento.

Sobre esse assunto, Bersch (2013) e Galvão Filho (2009) mencionam que devemos diferenciar a TA de outras tecnologias, como aquelas empregadas na área médica e de reabilitação. As tecnologias utilizadas nesses contextos visam favorecer a atuação dos profissionais em procedimentos avaliativos e em intervenções terapêuticas. Seguindo essa direção, tecnologias como: bisturí, broca, bola suíça, entre outros recursos que se destinem para esse fim, não podem ser considerados como recursos de TA, pelo fato de não contribuírem diretamente para a participação e engajamento social de pessoas que possuem comprometimentos funcionais. Porém, conforme a definição da ISO 9999 utilizada pelo Catálogo Nacional de Produtos de Tecnologia Assistiva do Ministério da Ciência, Tecnologia e Inovação esses materiais estão englobados dentro de uma grande área de equipamentos, a qual ainda não possibilita uma precisão em definir realmente quais são recursos de TA por contemplarem produtos como estimuladores e outros instrumentos de uso clínico. Por outro lado, em contextos de prática clínica, por exemplo, existem recursos de TA que ultrapassam o uso restrito da reabilitação ou clínico, são eles: cadeiras de rodas, muletas, andadores, bengalas, comunicadores alternativos. Tais recursos são utilizados pelos profissionais da saúde para favorecer a funcionalidade, relacionada à atividade e participação de pessoas com deficiência, visando contribuir para a sua autonomia, qualidade de vida e inclusão social, e poderiam assim ser classificados como TA.

Bersch (2013) e Rodrigues e Alves (2013) afirmam que, no âmbito educacional, também é comum que os profissionais da educação confundam as tecnologias educacionais como sendo de TA pelo fato de um determinado recurso computacional ou software educativo, que é amplamente utilizado pela população geral, possibilitar também o seu acesso por parte de pessoas que possuem deficiência.

Desse modo, não se convém designar o computador, por si só - sem a necessidade de adaptaçóes nos hardwares e sem o uso de softwares e mecanismos que promovam facilidades no acesso, como sendo um recurso de TA, apenas como um recurso acessível às necessidades de diferentes públicos. Caso o computador fosse classificado como um recurso de TA, o atributo de TA estaria condicionado à pessoa que manipula o recurso, ou melhor, designado a condição de deficiência, o que compreendemos como um grande equívoco. Pelas mesmas razóes, Galvão Filho (2013) discorda que os softwares educacionais acessíveis aos diferentes públicos sejam intitulados de TA e, para isso, apresenta determinados argumentos.

A imprecisão dos conceitos pode superestimar práticas a serem reconhecidas como uso de recursos de TA, e também subestimar aquelas que muitas vezes sáo alicerçadas e dependentes do recurso de TA, indiscriminando, em ambas as situaçóes, 
o real papel das estratégias didáticas do docente, dos materiais e equipamentos utilizados e das açôes promovidas com o aluno alvo. Assim, defendemos a importância de uma conceituação mais precisa da área de TA no país. Com a ampliação do entendimento sobre como se configura essa área e os recursos, práticas mais assertivas poderão ser realizadas, focalizando-se nos equipamentos realmente necessários e potentes a serem utilizados com cada indivíduo, em suas mais diversas atividades cotidianas.

$\mathrm{Na}$ atualidade, o aumento do financiamento, tanto para a pesquisa sobre desenvolvimento quanto para a aquisição de recursos, tem desempenhado papel principal nessa indefinição do conceito, porque a imprecisão interessa a vários grupos que podem ter acesso a esses recursos. Portanto, a indefinição do conceito é de natureza mais política do que teórica. Entretanto, as políticas deverão ser lapidadas de modo a realmente garantir o uso desses equipamentos a quem os necessita, e isso inclui aumentar a precisão do conceito de TA na legislação brasileira.

\section{Barreiras quanto ao acesso/provisão dos recursos de TA às escolas}

O número de pessoas com deficiência tem aumentado ao longo dos anos (BRASIL/ IBGE, 2010), e muitas delas necessitam do suporte de recursos de TA. Contudo, a questáo do acesso a esses recursos, em um contexto nacional, não é tão simples.

De acordo com Varela e Oliver (2013), uma das razóes que torna esse acesso complexo diz respeito ao alto custo dos produtos de TA, que é justificada pela importação de mercadorias de países estrangeiros e pela insuficiente produção nacional na área. Esse processo de aquisição da TA torna-se ainda mais complexo quando consideramos que a maior parte das pessoas com deficiência provém de famílias com rendas menos favorecidas (BRASIL, 2010), com baixas possibilidades de adquirir um recurso de TA por conta própria.

Convém-nos dizer que, tradicionalmente, as pessoas com deficiência recorrem aos recursos e serviços de TA disponibilizados pelo Sistema Único de Saúde (SUS), mesmo tendo conhecimento das inúmeras problemáticas relacionadas a esse serviço, tais como: burocracias documentárias (ALMEIDA FILHO, 2013) restrição de modelos e tipos de equipamentos de TA (VARELA; OLIVER, 2013) e elevado tempo de espera para obtenção dos recursos e também dos serviços de TA (ALMEIDA FILHO, 2013). Diante desse cenário, muito embora o SUS constitua-se como o principal ${ }^{1}$ órgáo governamental que disponibiliza os recursos e os serviços de TA para o usuário, a sua atuação nessa área é deficitária e requer mudanças emergenciais para que a população possa ter um serviço de qualidade.

Como alternativa para melhorar o funcionamento desse serviço de TA, seria preciso a ampliação do acesso aos recursos de TA, a descentralização dessa oferta para outras esferas governamentais e a viabilização de um trabalho numa perspectiva intersetorial. Dessa forma, não apenas se aliviaria a sobrecarga de atribuiçốes do SUS, como também viabilizaria o amparo desse serviço de TA mais próximo da realidade da população, permitindo assim identificar com maior clareza as suas reais necessidades. 
Somado a essas questôes, está o fato de que a maior parte dos 109 projetos sobre TA, financiados pelo CNPq (Conselho Nacional de Desenvolvimento Científico e Tecnológico) e pela FINEP (Financiadora de Estudos e Projetos) entre os anos 2005 e 2008, concentram-se no âmbito de apenas três estados brasileiros: Rio Grande do Sul, com 36 projetos (33\%), São Paulo, com 31 projetos $(28,4 \%)$ e Rio de Janeiro, com 17 projetos $(15,6 \%)$ (GARCÍA; GALVÃO FILHO, 2012). Assim, podemos deduzir que nos demais estados brasileiros há uma intensa alheação para a área de pesquisa e desenvolvimento de TA, o que deprecia tanto o avanço da produção do conhecimento científico-tecnológico, como também inibe o acesso da população que possui deficiência a esses recursos e serviços.

Tal situação tem sido objeto atual de preocupação do Governo Federal, que, por meio do plano Viver sem Limites - Plano Nacional dos Direitos da Pessoa com Deficiência ${ }^{2}$, tem a finalidade de contribuir para o equacionamento dos problemas e das insuficiências existentes nos serviços de atenção a pessoa com deficiência (BRASIL, 2011a). Dentro do escopo desse plano, está instituído o Programa de Inovação em Tecnologia Assistiva, que presume a interlocução de parcerias com as universidades, institutos de pesquisas e empresas que tenham por interesse desenvolver inovaçóes, com alcances de mercado, nas áreas de TA.

No Brasil, existem atualmente 53 Núcleos de Pesquisas em TA vinculados a Universidades e a Institutos Federais, conforme destaca o Centro de Tecnologia da Informação Renato Archer (CTIRA, 2014a), distribuídos nas cinco regiôes nacionais. Esses referidos Núcleos são orientados pelo Centro Nacional de Referência em Tecnologia Assistiva - CNRTA, que tem por desígnio estabelecer diretrizes e organizar a atuaçáo dos centros de produção científica e tecnológica do país, de modo a constituir uma rede cooperativa de pesquisa, desenvolvimento e inovação na área de TA (CTIRA, 2014b).

O plano Viver sem Limites conjetura ainda uma linha de crédito facilitado no Banco do Brasil - Crédito Acessibilidade (BRASIL, 2013a) para aquisição de produtos de TA, sendo os juros subsidiados pelo Governo Federal. Podem ser adquiridos, por exemplo, cadeiras de rodas motorizadas, computadores portáteis, adaptaçóes para veículos automotores, softwares de comunicação alternativa, dentre muitos outros recursos que auxiliem na equiparação das oportunidades de acesso à educação, à saúde, à inclusão social e à acessibilidade das pessoas com deficiência.

Implicaçóes quanto a efetivação do plano Viver sem Limites, aplicado ao campo da TA, pode ser observada no Programa Escola Acessível. De uma maneira específica, essa proposta governamental faculta a possibilidade das escolas, especificamente aquelas que possuem salas de recursos multifuncionais, requererem recursos de TA para o processo educativo de estudantes com deficiência no contexto escolar. A incumbência desse serviço de apoio é designada para a comunidade escolar - devendose levar em consideração "o ponto de vista e apreciaçáo da família, estudantes, equipe diretiva, professores (as) do AEE e da sala comum” (BRASIL, 2013b). Entende-se que a colaboração desse público na tomada de decisão é de fundamental importância, contudo, sabe-se que esse processo de prescrição de recursos envolve conhecimentos 
e habilidades específicas, que no caso precisaria também de uma equipe de profissionais especializados na área da TA. E ainda que a Resolução CNE/CEB N. 4/2009 (BRASIL, 2009b) atribua ao professor a função de estabelecer relações intersetoriais, com outros órgáos, para apoiar o seu ofício e consequentemente potencializar o processo de inclusão escolar, essa ação não é tão simples de se efetivar - uma vez que envolve questôes macroestruturais, isto é, de ordem política, que fogem simplesmente da vontade do querer fazer docente.

De forma equivalente, o Programa Implantação de Sala de Recursos Multifuncionais (BRASIL, 2011b), por meio do MEC, disponibilizou para as escolas públicas do ensino regular recursos de TA, visando apoiar a escolarização de estudantes público-alvo da Educação Especial ${ }^{3}$. O professor especializado é o profissional encarregado para atuar no desígnio dessa função. Todavia, esse profissional da Educação Especial no contexto da escola regular tem demonstrado não saber utilizar os referidos recursos de TA em suas práticas de trabalho, e a razão, na maioria das vezes, justifica-se pela falta de formação especializada na área (BERSCH, 2009; DOUNIS, 2013; HUMMEL, 2012; LOURENÇO, 2012; MANZINI, 2011; MANZINI, 2012). Assim, adentra-se no terceiro tópico emergente para o real uso dos recursos de TA na escola: a formação dos professores e demais membros da comunidade escolar.

\section{A formação dos professores e profissionais envolvidos com o atendimento aos alunos com deficiência no contexto escolar}

Por mais que se incentive a aplicação de recursos de TA para auxiliar o processo de escolarização de estudantes com deficiência, a lacuna na área de formação de recursos humanos nessa área é aparentemente instransponível. Aos professores têm sido requeridas habilidades e competências que se vinculam, antes de tudo, a um profissional "multifuncional" (VAZ, 2013), que deverá conhecer diversos métodos e técnicas para demandas específicas (FUMES et al, 2014).

Além do mais, tradicionalmente, os cursos de formação inicial de professores não abrangem conhecimentos tão específicos e diversificados que possam sustentar com efetividade o trabalho docente para o uso de recursos de TA, conforme argumentam Castro, Souza e Santos (2011) e Manzini (2013). Entretanto, essa fragilidade na formação docente, por sua vez, poderá trazer prejuízos ao desenvolvimento de seus alunos (GIROTO; POKER; OMOTE, 2012).

Entendemos que as práticas pedagógicas assumidas pelo professor durante o processo de escolarização podem influenciar no aprendizado dos seus estudantes e na construção de um ambiente escolar inclusivo. Todavia, reforçamos a ideia de que o professor não pode ser compreendido como o único responsável por esse processo, pois, em qualquer nível e modalidade de ensino que ocorra, a inclusão escolar implica em profundas mudanças que devem ocorrer na organização institucional, na remodelação do sistema educativo e pedagógico, entre outras, as quais estão muito além das possibilidades de ação do professor. 
Mediante esse contexto em que a área de TA se deflagra como ignorada pelos professores que não sabem utilizar seus recursos e tendo conhecimento da sua importância para o desenvolvimento educacional, a Secretaria de Formação Continuada, Alfabetização, Diversidade e Inclusão (SECADI), em parceria com as Instituiçôes de Ensino Superior que integram a Rede Nacional de Formação Continuada de Professores da Educação Básica (RENAFOR), tem desenvolvido cursos de formação continuada em nível de aperfeiçoamento e de pós-graduação lato sensu, oferecidos na modalidade à distância. Sobre essas formaçôes, Fumes et al (2014) mencionam que elas exibem um caráter emergencial e compensatório, que tem por intuito atender de forma aligeirada as lacunas e os pontos não enfatizados durante os cursos de formação inicial.

Logo, os resultados dessas formações têm causado poucas mudanças na prática pedagógica do professor, pois se encontram longe e em desarticulaçáo com a real necessidade do trabalho docente (ANJOS; CARVALHO, 2013; DAMASCENO; PEREIRA; ANDRADE, 2013; FUMES et al, 2013; MILANESI, 2013; OLIVEIRA et al, 2013; RABELO et al, 2013; SANTOS et al, 2013; SILVA; TARTUCI, 2013; TARTUCI et al, 2013). A maior repercussão que elas têm proporcionado diz respeito aos conhecimentos tipológicos sobre determinados recursos de TA, sem, contudo, contribuir para o domínio deles por parte dos professores. Porém, não basta conhecer o recurso, é preciso saber utilizá-lo de acordo com uma proposta educativa (RAIÇA, 2008).

Por tudo, esses modelos de formação continuada, fundamentados em conhecimentos restritivamente teóricos e desvinculados da prática profissional, não são suficientes para a melhoria do trabalho docente em Educação Especial. Os sistemas formativos devem permitir ao professor ser um personagem mais ativo em seu processo de formaçáo, para que dialogue com os seus pares e com profissionais de outras áreas do conhecimento, no intuito de identificar e buscar estratégias para equacionar os problemas que emergem das situaçôes cotidianas do processo de ensino-aprendizagem.

Para além da falta de uma formação docente especializada na área em questão, urge mencionar que esse não é o único fator que prejudica a efetiva implementação. Galvão Filho (2009) destaca outros fatores que prejudicam a operacionalização da TA na escola e que, por sua vez, podem causar problemas numa mesma proporção, a saber: fatores psicológicos, motivacionais, estéticos, sociais, ambientais, econômicos, entre outros, que por diversos motivos podem influenciar o uso, ou, até mesmo, o abandono desses recursos na escola.

Ademais, a participação do estudante no processo de implementação dos recursos de TA é considerada pré-requisito para lograr êxito. A não participação do estudante no processo de seleção e implementaçáo dos recursos de TA pode ter uma influência negativa e levar com que o recurso fique descontextualizado e sem propósito de uso (ALVES; MATSUKURA, 2011). Desse modo, a participaçáo do estudante é fundamental para que se evite o abandono ou a subutilização posterior do investimento oferecido em TA. De acordo com Lourenço (2012), esse envolvimento deve 
se iniciar na identificação das necessidades relacionadas a TA, prosseguir na seleção do recurso e consequente implementação/treinamento, perpetuando na avaliação e no acompanhamento do uso do recurso de TA pelo usuário.

A questâo do treinamento e acompanhamento é outro fator que tem implicado na efetiva implementação no contexto escolar. É importante apontar que os estudantes estão sendo conduzidos a utilizar os recursos de TA sem a sistematização de um serviço especializado, que proporcione autonomia para o uso nas diferentes atividades escolares (ALVES, 2009). Ademais, são quase que inexistentes as propostas para o acompanhamento do uso no contexto escolar e, de igual forma, são escassas as parcerias com serviços e profissionais de outras áreas do saber.

A necessidade de manutenção dos próprios recursos também pode implicar negativamente no uso dos recursos de TA no contexto educacional. Quando esses recursos estão com defeitos, é preciso pensar em outras estratégias ou disponibilizar diferentes recursos ao estudante, para que, durante o período de manutenção, existam possibilidades e isso náo cause desmotivação e prejuízos à participação do estudante no cotidiano escolar (ALVES; MATSUKURA, 2011; MENDES; LOURENÇO, 2010).

Em outros casos, mesmo com a necessidade e indicação de uso dos recursos de TA, vários estudantes não chegam nem a ter acesso a esses recursos. Dados do Observatório Nacional de Educação Especial (ONEESP) ${ }^{4}$ sobre o funcionamento nacional das SRM indicam que a implementação desses equipamentos e materiais se defronta com desafios relacionados à burocracia administrativa, que deixam os recursos de TA encaixotados a espera de um profissional técnico, que faça as suas devidas instalações (GALVÃO FILHO; MIRANDA, 2012; SILVA; CALHEIROS; FUMES, 2012; REIS, 2013). Assinalam ainda para o fato de muitos recursos de TA não terem sido entregues às escolas pelo Ministério da Educação, por meio do Programa Implantação de Salas de Recursos Multifuncionais.

Assim, diversos outros fatores estão envolvidos nesse processo e são tão importantes quanto a questão da qualificação profissional, recaída muitas vezes somente sobre o professor, devendo ser alvo de açôes com vistas ao uso efetivo desses recursos no ambiente educacional.

\section{Como então avançar sobre essas questões no país?}

Para avançar, primeiramente, há necessidade de uma conceituação de TA mais precisa, que contemple os contextos de vida da pessoa com deficiência, que direcione financiamentos e se auto sustente. Apesar do reconhecido progresso na proposição do CAT (BRASIL, 2007), a evolução na produção de conhecimento teórico e prático da área no país ao longo desses quase dez anos indicando barreiras a serem superadas, adicionada às dificuldades dos agentes financiadores contemplarem projetos que realmente atendam ao conceito proposto, reforça a indicação de um novo esforço pela definição de TA no Brasil. 
Em segundo lugar, revela-se necessária a adoção de políticas públicas que promovam de forma equitativa o acesso aos recursos de TA como direito, seja na escola, em casa, no trabalho, em ambientes de lazer, como em quaisquer outros locais de interesse da pessoa com deficiência.

Modelos de formação de professores e dos demais profissionais envolvidos nas diversas ações junto ao público-alvo da Educação Especial devem ser repensados, no intuito de que esses profissionais possam conhecer o recurso de TA e fazê-lo atingir o seu objetivo na garantia de ampliação de funcionalidade e participação social do sujeito, por todo o seu curso de vida.

Uma das formas de viabilizar essa formação de recursos humanos em TA pode ser via formação em serviço, que é um modelo destinado a romper com a dissociação constituída entre os conteúdos teóricos e o campo prático, como apontam Nóvoa (2009) e Tardif (2011). Os saberes científicos e pedagógicos devem emergir da própria prática da profissão docente, ao contrário da normatização antecipada de conteúdos que, com frequência nos cursos de formaçáo, sáo estabelecidos pela universidade e por seus formadores universitários.

$\mathrm{Na}$ área da Educação Especial, o modelo da consultoria colaborativa tem se destacado por priorizar essa abordagem de prática centrada no serviço. A consultoria colaborativa é uma estratégia destinada a resolver problemas educacionais relacionados ao processo de inclusão escolar e deve envolver a participação colaborativa de profissionais especializados e professores da escola comum (MENDES; ALMEIDA; TOYODA, 2011). Nessa relação entre esses profissionais, a igualdade nos papéis de atuação deverá ser uma evidência e sob nenhuma hipótese concentração do saber por determinada parte dos envolvidos com o processo de colaboraçáa. Tal proposta de serviço permite náo somente a equiparaçáo das oportunidades para os estudantes público-alvo da Educação Especial, mas também oportuniza a construção de habilidades profissionais de todos os envolvidos.

Os serviços de consultoria colaborativa prestados na área de TA, oferecidos tanto na modalidade presencial (DOUNIS, 2013; FRANÇANI; SIMÓES; BRACCIALLI, 2009; HUMMEL, 2012; LOURENÇO, 2012; PELOSI, 2008; SCHIRMER et al, 2010; TOYODA; CRUZ; LOURENÇO, 2009) quanto na modalidade à distância (CALHEIROS, 2015), têm apontado resultados positivos e indicam que os professores e demais profissionais envolvidos na escolarização do público-alvo da Educação Especial se apropriam do uso dos recursos de TA.

Contudo, as pesquisas também apontam um grande desafio para a formação desses profissionais, que é o da continuidade no uso dos recursos de TA, pois os dados obtidos demonstram que, após o término das consultorias oferecidas, ocorre também a descontinuidade no uso desses recursos (LOURENÇO, 2012; HUMMEL, 2012). Como alternativa viável para solução desse problema, recomenda-se a implementação de um serviço permanente de consultoria colaborativa escolar na área de TA para professores, com a finalidade de estimular e garantir o uso continuado desses recursos em sala de aula. 
Compreende-se, também, que a consultoria colaborativa não deva ser a única forma de garantir apoio à escola inclusiva e à formação de profissionais na área de TA, pois as necessidades e peculiaridades dos ambientes educacionais são múltiplas, variando entre localidades. Assim, outros serviços de suporte devem estar à disposição das escolas, dentro de um contínuo de serviços, visando apoiar o processo de inclusão escolar.

Para finalizar, sugere-se que ocorra um aprofundamento sobre modelos de serviços, para que se possa projetar açóes importantes de implementação dessa prática na realidade das escolas brasileiras, de modo a garantir que não apenas os recursos estejam disponíveis, mas também a forma de os implementar, e isso pode, consequentemente, impulsionar a formação e a prestação de serviços para a área.

\section{Referências}

ALMEIDA FILHO, N. M. Contextos, impasses e desafios na formação de trabalhadores em Saúde Coletiva no Brasil. Ciênc. saúde coletiva [online], Rio de Janeiro, v.18, n.6, p. 1677-1682, 2013.

ALVES, A. C. J. Percepçáo de alunos com paralisia cerebral sobre o uso de recursos de tecnologia assistiva na escola regular. 2009. 168f. Dissertação (Mestrado em Educação Especial) - Universidade Federal de São Carlos, São Carlos, 2009.

ALVES, A. C. J.; MATSUKURA, T. S. percepção de alunos com paralisia cerebral sobre o uso de recursos de tecnologia assistiva na escola regular. Rev. Bras. Ed. Esp., Marília, v.17, n.2, p.287-304, 2011.

ANJOS, I. R. S.; CARVALHO, T. S. S. Observatório de educação especial em Sergipe. In: IIIENCONTRO DO OBSERVATÓRIO NACIONAL DE EDUCAÇÃO ESPECIAL, 3., 2013, São Paulo. Anais... São Paulo: UFSCar/USP, 2013. 1 CD-ROM.

BERSCH, R. C. R. Design de serviço de tecnologia assistiva em escolas públicas. 2009. 231f. Dissertação (Mestrado em Design) - Programa de Pós-Graduação em design, Universidade Federal do Rio Grande do Sul, Porto Alegre, 2009.

BERSCH, R. C. R. Introduçáo à Tecnologia Assistiva. Porto Alegre: Assistiva - Tecnologia e Educação, 2013. Disponível em: <http://www.assistiva.com.br/Introducao_Tecnologia_Assistiva.pdf>. Acesso em: 22 jun. 2014.

BRASIL. Decreto n. 3.298, de 20 de dezembro de 1999. Brasília, DF: Diário Oficial da Uniăo [da] República Federativa do Brasil, 1999. Disponível em: <http://www.planalto.gov.br/ccivil_03/decreto/D3298.htm>. Acesso em: 22 jun. 2014.

BRASIL. Decreto n. 5.296, de 2 de dezembro de 2004. Brasília, DF: Diário Oficial da Uniāo da República Federativa do Brasil, 2004. Disponível em: <http://www.planalto.gov.br/ccivil_03/_ato2004-2006/2004/decreto/ d5296.htm>. Acesso em: 22 jun. 2014.

BRASIL. Ata VII - Comitê de Ajudas Técnicas - CAT. Secretaria Especial dos Direitos Humanos da Presidência da República (CORDE/SEDH/PR). 2007. Disponível para download em: <https://docs.google.com/ viewer?a=v\&pid=sites\&srcid=ZGVmYXVsdGRvbWFpbnx0ZWNub2xvZ2lhYXNzaXN0aXZhY29tYnJ8Z3g6MTdiZWQyY2IzYTE3OWJmZg >. Acesso em: 22 ago. 2013.

BRASIL. Subsecretaria Nacional de Promoçáo dos Direitos da Pessoa com deficiência. Comitê de Ajudas Técnicas. Tecnologia Assistiva. Brasília: CORDE, 2009a.

BRASIL. MEC. Resoluçáo n. 4, de 2 de outubro de 2009. Brasília, DF: MEC, 2009 b.

BRASIL. IBGE. Censo Demográfico 2010: Características gerais da populaçáo, religião e pessoas com deficiência. Rio de Janeiro: IBGE, 2010. Disponível em: <http://biblioteca.ibge.gov.br/visualizacao/periodicos/94/ cd_2010_religiao_deficiencia.pdf>. Acesso em: 22 jun. 2014.

BRASIL. Decreto n. 7.612, de 17 de novembro de 2011. Brasília, DF: Diário Oficial da União [da] República Federativa do Brasil, 2011a. Disponível em: < http://www.planalto.gov.br/ccivil_03/_Ato2011-2014/2011/ Decreto/D7612.htm>. Acesso em: 22 jun. 2014.

BRASIL. Decreto n. 7.611, de 17 de novembro de 2011. Brasília, DF: MEC, 2011b. Disponível em: <http:// www.planalto.gov.br/ccivil_03/_Ato2011-2014/2011/Decreto/D7611.htm>. Acesso em: 22 jun. 2014. 
BRASIL. Viver sem Limites: Plano Nacional dos Direitos da Pessoa com Deficiência. Brasília, DF: SDH -PR/SNPD, 2013a. Disponível em: <http://www.pessoacomdeficiencia.gov.br/app/sites/default/files/arquivos $\%$ 5Bfield_generico_imagens-filefield-description\%5D_0.pdf>. Acesso em: 23 jun. 2014.

BRASIL. Documento orientador programa escola acessível. Brasília, DF: SECADI, 2013b. Disponível em: $<$ http://portal.mec.gov.br/index.php?option=com_docman\&view=download\&alias=13290-doc-orient2013\&category_slug=junho-2013-pdf\&Itemid=30192>. Acesso em: 02 abr. 2016.

CALHEIROS, D. S. Consultoria colaborativa à distância em tecnologia assistiva para professores de salas de recursos multifuncionais. 2015. 165f. Dissertação (Mestrado em Educação Especial), Universidade Federal de São Carlos, São Carlos, 2015.

CASTRO, A. S. A.; SOUZA, L. R.; SANTOS, M. C. Proposiçôes Teóricas para a Inclusão da Tecnologia Assistiva no Currículo Escolar da Educação Básica. Sitientibus, Feira de Santana, n. 44, p. 145-158, 2011.

CENTRO DE TECNOLOGIA DA INFORMAÇÃO RENATO ARCHER. Centro Nacional de Referência em Tecnologia Assistiva: Apresentaçẫo. Campinas: CTIRA, 2014a. Disponível em: <http://www.cti.gov.br/ cnrta/apresentacao-cnrta>. Acesso em: 22 dez. 2014.

CENTRO DE TECNOLOGIA DA INFORMAÇÃO RENATO ARCHER. Núcleos de Pesquisa em Tecnologia Assistiva. Campinas: CTIRA, 2014b. Disponível em: <http://www.cti.gov.br/component/content/ article?id=511>. Acesso em: $22 \mathrm{dez} .2014$.

DAMASCENO, A. R. PEREIRA, A. S. ANDRADE, P. F. Formaçáo docente: para quê? As experiências de professores de salas de recursos multifuncionais de Nova Iguaçu/RJ. In: III ENCONTRO DO OBSERVATÓRIO NACIONAL DE EDUCAÇÃO ESPECIAL, 3, 2013, São Paulo. Anais... São Paulo: UFSCar/USP, 2013. 1 CD-ROM.

DOUNIS, A. B. Atividade docente e inclusão: as mediaçóes produzidas pela consultoria colaborativa. 2013. 180f. Dissertação (Mestrado em Educação), Universidade Federal de Alagoas, Maceió, 2013.

EASTIN. Rede de informaçáo europeia sobre tecnologia para deficiência e autonomia. Comissão Europeia, 2005. Disponível em: <http://www.eastin.info/home.aspx?pg=proj ect\&pg1=description\&ln=es. Acesso em 22 jun. 2014.

EUSTAT. Educaçáo em Tecnologias de Apoio para Utilizadores Finais: Linhas de Orientaçáo para Formadores. Comissão Europeia, 1999. Disponível em: <http://www.siva.it/research/eustat/eustgupt.html>. Acesso em 22 jun. 2014.

FUMES, N. L. F.; CALHEIROS, D. S.; MERCADO, E. L. O.; SILVA, F. K. R.; BARBOSA, M. O.; SANTOS, S. D. G. A implantação das salas de recursos multifuncionais no município de Maceió/Alagoas: sintetizando os resultados. In: III ENCONTRO DO OBSERVATÓRIO NACIONAL DE EDUCAÇĀO ESPECIAL, 3., 2013, São Paulo. Anais... São Paulo: UFSCar/USP, 2013. 1 CD-ROM.

FUMES, N. L. F.; CALHEIROS, D. S.; MERCADO, E. L. O.; SILVA, F. K. R.; BARBOSA, M. O.; SANTOS, S. D. G; A formação continuada de professores de salas de recursos -multifuncionais do município de Maceiól AL. Revista Teias, Rio de Janeiro, v. 14, n. 35, p. 71-87, 2014.

FRANÇANI, C. O.; SIMÓES, E. M.; BRACCIALLI, L. M. P. Tecnologia assistiva: desenvolvimento de recursos de baixo custo. Revista Ciência em Extensáo, São Paulo, v. 5, n. 2, p.108, 2009.

GALVÃO FILHO, T. A. Tecnologia Assistiva para uma Escola Inclusiva: Apropriaçáo, Demandas e Perspectivas. 2009. 346f. Tese (Doutorado em Educação), Faculdade de Educação, Universidade Federal da Bahia, Salvador, 2009.

GALVÃO FILHO, T. A; MIRANDA, T. G. Tecnologia Assistiva e salas de recursos: análise crítica de um modelo. In: GALVÃO FILHO, T. A.; MIRANDA, T. G. (Orgs.). O professor e a educaçáo inclusiva: formação, práticas e lugares. Salvador: EDUFBA, 2012, p. 247-266.

GALVÃO FILHO, T. A. A construção do conceito de Tecnologia Assistiva: alguns novos interrogantes e desafios. Revista Entreideias, Salvador, v. 2, n.1, p. 25-42, 2013.

GARCÍA, J. C. D.; GALVÃO FILHO, T. A. Pesquisa Nacional de Tecnologia assistiva. São Paulo: ITS BRASIL/MCTI-SECIS, 2012.

GIROTO, C. R. M.; POKER, R. B.; OMOTE, S. Educação Especial, formação de professores e o uso de tecnologias de informação e comunicaçáo: a construção de práticas pedagógicas inclusivas. In: GIROTO, C. R. M.; POKER, R. B.; OMOTE, S. (Org.). As tecnologias nas práticas pedagógicas inclusivas. São Paulo: Cultura Acadêmica/FEU/UNESP e Oficina Universitária, 2012, v. 1, p. 11-22. 
HUMMEL, E. I. Formaçáo de professores das salas de recursos multifuncionais para o uso da tecnologia assistiva. 2012. 231f. Tese (Doutorado em Educação), Faculdade de Filosofia e Ciências, UNESP, Marília, 2012.

INTERNATIONAL ORGANIZATION FOR STANDARDIZATION. ISO 9999. Disponível em: <http:// www.siva.it/ftp/en_iso_9999.zip>. Acesso em: 29 jan 2015.

LAUAND. B. A. Fontes de informaçáo sobre tecnologia assistiva para favorecer a inclusáo escolar de alunos com necessidades especiais. 2005. 210f. Tese (Doutorado emEducação Especial), Universidade Federal de São Carlos, São Carlos, 2005.

LOURENÇO, G. F. Avaliaçáo de um programa de formaçáo sobre recursos de alta- tecnologia assistiva e escolarizaçáo. 2012. 258f. Tese (Doutorado em Educação Especial), Centro de Ciências Humanas, Universidade Federal de São Carlos, 2012.

MANZINI, E. J. Formação de Professores e Tecnologia Assistiva. In: CAIADO, K. R. M.; JESUS, D. M.; BAPTISTA, C. R. (Orgs.). Professores e educaçáo especial: formação em foco. Porto Alegre: Mediação, 2011, v. 2 , p. $45-63$.

MANZINI, E. J. Formação do professor para trabalhar com recursos de tecnologia assistiva: um estudo de caso em Mato Grosso. Educaçáo e Fronteiras On-Line, Dourados, v.2, n.5, p.98-113, 2012.

MANZINI, E. J. Formação do professor para o uso de tecnologia assistiva. Cadernos de Pesquisa em Educaçấo, Vitória, v. 18, n. 36, p. 11-32, jul./dez. 2013.

MENDES, E. G.; ALMEIDA, M. A.; TOYODA, C. Y. Inclusão escolar pela via da colaboração entre educação especial e educação regular. Educar em Revista (Impresso), Curitiba, v. 41, p. 80-93, 2011.

MENDES, E. G.; LOURENÇO, G. F. O uso dos recursos e alta tecnologia assistiva no projeto Alta TA \& Inclusão: possibilidades e desafios In: Margens ao centro: perspectivas para as políticas e práticas educacionais o contexto da educação especial inclusiva. Araraquara: Junqueira \& Marin, 2010, p. 205-225.

MILANESI. As salas de recursos multifuncionais em Rio Claro/SP. In: III ENCONTRO DO OBSERVATÓRIO NACIONAL DE EDUCAÇÃO ESPECIAL, 3, 2013, São Paulo. Anais... São Paulo: UFSCar/USP, 2013. 1 CD-ROM.

NÓVOA, A. Para uma formação de professores construída dentro da profissão. In: NÓVOA, A. Professores: imagens do futuro presente. Lisboa: Educa, 2009. p. 25-46.

OLIVEIRA, T. C. B. O.; SANTOS, F. R.; COSTA, D. B.; SANTOS, E.; CONCEIÇÃO, M. B.; SILVA, N. S.; CAMPOS, T. S. Formação de professores para a inclusão escolar. In: III ENCONTRO DO OBSERVATÓRIO NACIONAL DE EDUCAÇĀ̃ ESPECIAL, 3, 2013, São Paulo. Anais... São Paulo: UFSCar/USP, 2013. 1 CD-ROM.

PELOSI, M. B. Inclusáo e Tecnologia Assistiva. 2008. 303f. Tese (Doutorado em Educação), Centro de Educação e Humanidades, UERJ, Rio de Janeiro, 2008.

PUBLIC LAW 108-364. 108th Congress, 2004. Disponível em: <https://www.gpo.gov/fdsys/pkg/STATUTE-118/pdf/STATUTE-118-Pg1707.pdf>. Acesso em 04 dez. 2007.

RABELO, L. C. C.; OLIVEIRA, I. A; RODRIGUES, A. S.; BARROSO, N. E.; ALMEIDA, M. L. Observatório de educação especial: a implantação, organização e funcionamento das salas de recursos multifuncionais em Marabá-PA. In: III ENCONTRO DO OBSERVATÓRIO NACIONAL DE EDUCAÇ̃̃ ESPECIAL, 3, 2013, São Paulo. Anais... São Paulo: UFSCar/USP, 2013. 1 CD-ROM.

RAIÇA, D. Tecnologia e Educação Inclusiva. In: RAIÇA, D (Org.). Tecnologias para a educaçáo inclusiva. São Paulo: Avercamp, p. 19-34, 2008.

REIS, C. V. O uso de tecnologia assistiva em salas de recursos multifuncionais no sudeste goiano. In: I SIMPÓSIO INTERNACIONAL DE ESTUDOS SOBRE A DEFICIÊNCIA, 1, 2013, São Paulo. Anais... São Paulo: USP, 2013. 1 CD-ROM.

RODRIGUES, P. R.; ALVES, L. R. G. Tecnologia Assistiva: uma revisão do tema. Holos, Natal, v. 6, n.29, p. 170-180, 2013

SANTOS, M. C.; SOUZA, L. R.; ALMEIDA, I. C. A. SOUZA, Z. F. J. O olhar sobre a formação de professores das salas de recursos multifuncionais (SRM) no município de Feira de Santana. In: III ENCONTRO DO OBSERVATÓRIO NACIONAL DE EDUCAÇÃO ESPECIAL, 3, 2013, São Paulo. Anais... São Paulo: UFSCar/USP, 2013. 1 CD-ROM. 
SCHIRMER, C. R.; ARAÚJO, C. A.; WALTER, C. F.; NUNES, L. R. O. P.Formação continuada em serviço de professores: uma proposta de colaboração entre educação especial, educação comum e clínica. In: IV CONCRESSO BRASILEIRO DE EDUCAÇÃ̂ ESPECIAL, 4, 2010, São Carlos. Anais... São Carlos: UFSCar, 2010. 1 CD-ROM.

SILVA, M. R.; TARTUCI, D. Formação dos professores do atendimento educacional especializado do sudeste goiano. In: III ENCONTRO DO OBSERVATÓRIO NACIONAL DE EDUCAÇÃO ESPECIAL, 3, 2013 , São Paulo. Anais... São Paulo: UFSCar/USP, 2013. 1 CD-ROM.

SILVA, F. K. R.; CALHEIROS, D. S.; FUMES, N. L. F. O professor da educação especial de Maceió frente ao trabalho nas salas de recursos multifuncionais. In: V CONCRESSO BRASILEIRO DE EDUCAÇÃO ESPECIAL, 5, 2012, São Carlos. Anais... São Carlos: UFSCar, 2012. 1 CD-ROM.

TARDIF, M. Saberes Docentes e Formação Profissional. 12. ed. Petrópolis, Vozes, 2011.

TARTUCI, D.; BERGAMASCHI, E. M. M.; FLORES, M. M. L. CARDOSO, C. R. Salas de recursos multifuncionais em Goiás: formação docente, organização do trabalho pedagógico e tecnologia assistiva. In: III ENCONTRO DO OBSERVATÓRIO NACIONAL DE EDUCAÇÃO ESPECIAL, 3, 2013, São Paulo. Anais... São Paulo: UFSCar/USP, 2013. 1 CD-ROM.

TOYODA, C. Y.; LOURENÇO, G. F. Educação Inclusiva: o contexto da terapia ocupacional In: Temas em educaçáo especial: múltiplos olhares. Araraquara: Junqueira e Marin, 2008, p. 44-52.

TOYODA, C. Y.; LOURENÇO, G. F; CRUZ, D. M. C.; LOURENÇO, G. F. Tecnologia assistiva de baixo custo: relato de consultoria colaborativa. In: V CONGRESSO BRASILEIRO MULTIDISCIPLINAR DE EDUCAÇÃO ESPECIAL, 5, 2009, Londrina. Anais... Londrina: UEL, 2009. 1 CD-ROM.

VARELA, R. C. B.; OLIVER, F. C. A utilizaçấo de Tecnologia Assistiva na vida cotidiana de crianças com deficiência. Ciênc. saúde coletiva [online], Rio de Janeiro, v.18, n.6, p. 1773-1784, 2013.

VAZ, K. O professor de educaçáo especial nas políticas de perspectiva inclusiva no Brasil: concepções em disputa. 2013. 237f. Dissertaçẫo (Mestrado em Educação) - Centro de Ciências da Educação da Universidade Federal de Santa Catarina, Florianópolis, 2013.

\section{Notas}

${ }^{1}$ Além do SUS, outros órgãos públicos disponibilizam recursos e serviços de tecnologia assistiva, a saber: Instituto Nacional de Seguridade Social (INSS) e o Ministério da Educação (MEC).

${ }^{2}$ Foi elaborado a partir do diálogo e da participação de mais de 15 Ministérios e do Conselho Nacional dos Direitos das Pessoas com Deficiência - CONADE (BRASIL, 2011a).

${ }^{3}$ Além do Programa Escola Acessível e do Programa Implantação de Sala de Recursos Multifuncionais, há no MEC recursos do Fundo de Manutenção e Desenvolvimento da Educação Básica (FUNDEB) duplo e no Plano de Açôes Articuladas (PAR) que podem ser utilizados para aquisição e disponibilização de recursos de TA na escola.

${ }^{4}$ Rede formada por pesquisadores, provenientes de diversos estados e instituiçôes de ensino superior de todo o Brasil, que desenvolvem um estudo em rede nacional sobre as Salas de Recursos Multifuncionais nas escolas comuns, com coordenação nacional da Profa. Dra ${ }^{\mathrm{a}}$. Enicéia Gonçalves Mendes.

\section{Correspondência}

Enicéia Gonçalves Mendes - Universidade Federal de Sáo Carlos, Centro de Educação e Ciências Humanas, Departamento de Psicologia. Bairro: Monjolinho. CEP: 13565-905, Săo Carlos, São Paulo, Brasil.

E-mail: davidcalheiros@yahoo.com - eniceia.mendes@gmail.com - gerusalourenco@gmail.com

Recebido em 16 de julho de 2015

Aprovado em 04 de abril de 2016 
